\title{
Managing dialysis patients who develop anemia caused by chronic kidney disease: focus on peginesatide
}

This article was published in the following Dove Press journal:

International Journal of Nanomedicine

24 August 2013

Number of times this article has been viewed

\author{
Amanda Valliant \\ R Michael Hofmann \\ Division of Nephrology, University \\ of Wisconsin, Madison, WI, USA
}

\begin{abstract}
Anemia in chronic kidney disease is a prevalent and expensive problem in the United States, and it is well documented that anemia worsens as glomerular filtration rates decline. The complications of severe anemia in this patient population contribute significantly to their overall morbidity with increased cardiovascular complications, decreased quality of life, and increased dependence on transfusions to maintain adequate hemoglobin levels. Erythropoietinstimulating agents (ESAs) have revolutionized the treatment of anemia in this population, but there has been a great deal of controversy surrounding the quest for the ideal hemoglobin target. In addition, there are economic and practice management implications where anemia treatment is concerned, with ongoing refinement of Centers for Medicare and Medicaid Services-bundled payments. One of the newest additions to the arsenal used to fight anemia in end-stage renal disease patients is peginesatide (Omontys), a synthetic, PEGylated, peptide-based ESA that acts by stimulating the erythropoietin receptor. The role of peginesatide in the future treatment of anemia in chronic kidney disease remains uncertain, with new safety concerns being brought to attention as it emerges on the market, prompting a national recall.
\end{abstract}

Keywords: anemia, chronic kidney disease, peginesatide

\section{Introduction}

Anemia in chronic kidney disease (CKD) has long been a substantial problem for both patients and providers. Currently there are more than 8 million American adults with CKD stage 3 or greater (glomerular filtration rate [GFR] less than $60 \mathrm{~mL} / \mathrm{min} / 1.73 \mathrm{~m}^{2}$ ) and anemia. Current prevalence is estimated to range between $18 \%$ in stage 3 disease to near $60 \%$ in stage $4-5$ (GFR less than $\left.30 \mathrm{~mL} / \mathrm{min} / 1.73 \mathrm{~m}^{2}\right) .{ }^{1}$ The incidence and prevalence of end-stage renal disease (ESRD) continues to increase in the United States, and it is well documented that anemia worsens as GFR declines due to less native erythropoietin production. Erythropoietin is a glycoprotein hormone synthesized by the kidneys in response to hypoxia. Erythropoietin regulates the proliferation, differentiation, and survival of erythroid progenitor cells and thereby controls erythrocyte levels. ${ }^{2}$ Multiple factors contribute to anemia in the patient with ESRD including decreased erythrocyte half-life in the uremic milieu, decreased gut absorption of iron and chronic blood loss in the tubing set with each dialysis treatment. In addition, it is unclear if anemia in patients with renal disease is entirely due to decreased production of erythropoietin or if there is a derangement in oxygen-sensing capacity leading to a secondary decrease in erythropoietin production. ${ }^{3}$ However, anemia in ESRD patients has been clearly shown to increase the incidence of cardiovascular complications, ${ }^{4}$ reduce quality of life (primarily by decreasing physical capacity), and 
impair cognitive function. ${ }^{5}$ Erythropoietin-stimulating agents (ESAs) are considered the standard of care for treatment of anemia in ESRD patients. ${ }^{6}$

\section{History of ESA usage and target hemoglobin goals}

The introduction of recombinant human erythropoietin (rhuEPO) to clinical practice in 1989 in the United States revolutionized the treatment of chronic anemia in this patient population. Prior to the introduction of rhuEPO, patients were transfused only when they became clinically symptomatic. However, this practice put many patients at risk for secondary complications including volume and iron overload, hyperkalemia, allosensitization, transfusion reactions, and blood-borne infections. ${ }^{7}$ Prior to 1989 , dialysis patients were transfusion-dependent and suffered the debilitating symptoms consistent with hemoglobin levels chronically in the $6-7 \mathrm{~g} / \mathrm{dL}$ range. ${ }^{8}$ The initial response to erythropoietin treatment was dramatic, with improvements in quality of life as well as the physiologic benefits associated with fewer transfusions and improved hemoglobin levels. ${ }^{6,9,10}$ Consequently, the use of erythropoietic-stimulating agents to correct anemia in the ESRD population exploded over the next few years. Observational studies noting that patients with higher hemoglobin levels at dialysis initiation had decreased hospitalization rates and mortality spurred a more aggressive approach to correcting anemia. ${ }^{11}$ Not surprisingly, the concept of trying to achieve near-normal hemoglobin levels through higher dose ESAs was particularly appealing to nephrologists who now had a tool available to help reach this goal.

However, in recent years, the optimal target level of hemoglobin has been the subject of a great deal of debate within the nephrology community. Several large, randomized trials investigating dosing strategies attempting to normalize hemoglobin levels have increased morbidity and mortality. These trials also demonstrated increased thromboembolism rates (both arterial and venous) and stroke with higher doses of ESA administration. ${ }^{12,13}$

The first study to incite concern about normalizing blood counts was the aptly named Normal Hematocrit Cardiac Trial. ${ }^{14}$ This study enrolled over 1200 patients known to have heart failure or ischemic heart disease and hematocrit levels of $27 \%-33 \%$ on epoetin treatment. The patients in the normal hematocrit group received escalating doses of epoetin to achieve and maintain levels of $42 \% \pm 3 \%$, while the low hematocrit group received doses adjusted to maintain hematocrit levels of $30 \% \pm 3 \%$. The study had a planned duration of 3 years, but was stopped after 14 months due to concerns when interim analysis demonstrated more primary end-point adverse events, including death or first nonfatal myocardial infarction (MI) in the normal hematocrit patients. Further data analysis of this study failed to demonstrate a clear relationship between either hematocrit level or epoetin dosing and mortality. ${ }^{13}$ Target hemoglobin levels for patients with anemia secondary to CKD remained nebulous. A Cochrane meta-analysis of 19 randomized controlled trials comprising almost 2700 patients demonstrated that those with hemoglobin targets above $13 \mathrm{~g} / \mathrm{dL}$ were associated with higher all-cause mortality than those with targets $<12 \mathrm{~g} / \mathrm{dL} .{ }^{15}$ This analysis drew criticism because it included one dominant trial in hemodialysis patients who had preexisting cardiac disease. A second meta-analysis involving five randomized controlled and 11 uncontrolled trials with over 25,000 patients was published the same year examining the impact of ESAs on clinical end points and found that increasing hemoglobin from $<8$ to $>11 \mathrm{~g} / \mathrm{dL}$ was associated with decreases in transfusion rates, number of units transfused, and hospital rates and lengths of stay as well as increases in all measured quality of life parameters; no data on survival benefit was examined. ${ }^{16}$

In an effort to clarify the appropriate hemoglobin goal for ESA use, two randomized controlled trials were conducted in CKD patients not yet on dialysis to examine the effect of normalizing hemoglobin on cardiovascular end points and death. The first was the Correction of Hemoglobin and Outcomes in Renal Insufficiency (CHOIR) trial, randomizing 1432 patients to hemoglobin targets of $11.3 \mathrm{~g} / \mathrm{dL}$ versus $13.5 \mathrm{~g} / \mathrm{dL}$. The trial was terminated early by the data and safety monitoring board due to a trend towards increased composite cardiovascular events in the high hemoglobin target group and with no statistical probability of showing an appreciable difference in quality of life assessment scores. Subsequently, the authors concluded that the higher hemoglobin target conferred increased risk with no benefit as compared to the lower hemoglobin target of $11.3 \mathrm{~g} / \mathrm{dL}$. The Cardiovascular Risk Reduction by Early Anemia Treatment with Epoetin Beta (CREATE) trial followed, with 603 CKD patients randomized to hemoglobin targets of $13-15 \mathrm{~g} / \mathrm{dL}$ versus $10.5-11.5 \mathrm{~g} / \mathrm{dL}$. Ultimately the findings demonstrated no significant difference in cardiovascular events and left ventricular mass index after 3 years, but progression to dialysis and hypertensive episodes were more frequent in the high hemoglobin group and the authors concluded that early and complete correction of hemoglobin levels with epoetin therapy confers no benefit. ${ }^{12,13}$ Secondary analyses of both 
major trials have since been published with some interesting findings, including the suggestion that patients randomized to a higher hemoglobin level who achieved that target did better than those who did not, and there may be a negative outcome associated with the higher epoetin dosing in poor responders. ${ }^{17}$ It appears those at greatest risk of adverse events are the subset of patients on increasingly higher doses of ESA, but are consistently unable to reach target hemoglobin goals. Multiple explanations have been hypothesized, but it may indicate that a standardized, protocol-driven approach to ESA management focused on increasing doses of ESA to meet hemoglobin goals may harm some patients. Those that, essentially, are "nonresponders" are likely to have doses decreased or held rather than increased. Further research in this area is certainly warranted.

Updated National Kidney Foundation/Kidney Disease Outcomes Quality Initiative guidelines and recommendations for clinical practice concerning hemoglobin targets were published in 2007. They were modified after the CHOIR and CREATE trials had been released and the US Food and Drug Administration (FDA) had released new prescribing information and advisories regarding ESA use. Recommendations were for a hemoglobin target of $11-12 \mathrm{~g} / \mathrm{dL}$ and not greater than $13 \mathrm{~g} / \mathrm{dL}$, with emphasis on the need to weigh risks and benefits of ESA use in individual patients. ${ }^{18}$ FDA recommendations were to keep hemoglobin between 10-12 g/dL and to minimize ESA use where possible, which is accomplished primarily by aiming for higher transferrin saturation and ferritin goals and increased use of parenteral iron formulations.

During this time, the Trial to Reduce Cardiovascular Events with Aranesp Therapy (TREAT) trial was ongoing. This international trial enrolled more than 4000 patients with CKD, anemia, and type 2 diabetes mellitus. Anemia was defined as a hemoglobin $<11 \mathrm{~g} / \mathrm{dL}$. To date, this is the only randomized, double-blinded, placebo-controlled trial of anemia treatment in patients with CKD. Primary end points included death or nonfatal cardiovascular events, Patients were randomized to either darbepoetin alfa to maintain a hemoglobin level of $13 \mathrm{~g} / \mathrm{dL}$ or to placebo. The placebo group was to receive darbepoetin alfa if the hemoglobin fell lower than $9 \mathrm{~g} / \mathrm{dL}$, but it was then discontinued when the hemoglobin went above $9 \mathrm{~g} / \mathrm{dL}$. The risk of death, nonfatal cardiovascular events, and progression to renal failure were not different between the two groups. The group treated with darbepoetin reported slightly higher quality of life scores, but also had an increased risk of stroke with 101 patients in the treatment and 53 patients in the placebo group experiencing a stroke during the study (hazard ratio [HR], 1.92; 95\% confidence interval $[\mathrm{CI}]: 1.38$ to $2.68 ; P<0.001) .{ }^{19}$

These studies prompted a great deal of discussion regarding ESA use in CKD and ESRD patients. Currently, experts have advocated minimizing ESA dosing and increased use of parenteral iron to target ferritin goals upwards of $800 \mu \mathrm{g} / \mathrm{L} .{ }^{20}$ For most practicing nephrologists, hemoglobin levels $<9 \mathrm{~g} / \mathrm{dL}$ will prompt treatment with ESAs. The rates of transfusion as "rescue" treatment have risen accordingly in recent years. ${ }^{21}$ As might be expected, patients treated with parenteral iron and ESAs require significantly fewer transfusions than those who are not, among both the CKD and ESRD populations. Mean hemoglobin levels among American patients on dialysis have declined as the numbers of patients with hemoglobin levels $<10 \mathrm{~g} / \mathrm{dL}$ has increased. ${ }^{22}$

In August 2012, a long-awaited supplemental update to the Kidney Disease: Improving Global Outcomes clinical guidelines for anemia in CKD was published, incorporating new evidence and recommendations based on published data through March of 2012. Recommendations for dialysis patients include initiation of ESA therapy when the hemoglobin falls between $9-10 \mathrm{~g} / \mathrm{dL}$ to avoid hemoglobin levels $<9 \mathrm{~g} / \mathrm{dL}$. The goal is to keep hemoglobin levels between 10-11.5 g/dL with recommendations to avoid hemoglobin levels higher than $11.5 \mathrm{~g} / \mathrm{dL}$ during ESA treatment except in specific patients whose quality of life is improved at levels greater than $11.5 \mathrm{~g} / \mathrm{dL}$. Recommendations also advised against hemoglobin targets $>13 \mathrm{~g} / \mathrm{dL}$ in any patient. Guidelines also recommend iron supplementation for patients with transferrin saturation $<30 \%$ and ferritin levels $<500 \mu \mathrm{g} / \mathrm{L}$.

In CKD patients, it is recommended not to start ESA for patients with hemoglobin $>10 \mathrm{~g} / \mathrm{dL}$; in those patients who fall below this threshold, it is suggested that a patientspecific risk and benefit analysis be undertaken prior to ESA administration. This risk-to-benefit analysis should consider transfusion risks, symptoms attributable to anemia, prior response to iron therapy, and the rate of hemoglobin decline. In all CKD patients with anemia, iron supplementation should be administered for transferrin saturation $<30 \%$ and ferritin levels $<500 \mu \mathrm{g} / \mathrm{L}$ in patients without active systemic infections. In practice, it is often difficult to attain adequate iron saturation without exceeding recommendations for ferritin levels. Based on these recommendations, transferrin saturation and ferritin levels should be assessed prior to initiation of ESA, quarterly in patients on stable ESA doses, and more frequently when ESA dosing is being adjusted. ${ }^{23}$ 


\section{Economic and practice management considerations}

A discussion of anemia treatment in CKD and ESRD is not complete without consideration of the economic implications for anemia treatment in the era of bundled payments, performance-based reimbursement structures and a rapidly changing medical economic climate. Care for patients with ESRD is expensive and continues to consume a disproportionately large portion of Medicare costs. In 2010, costs for ESRD services consumed $6.3 \%$ of the total Medicare budget while serving less than $0.5 \%$ of the population. Currently, dialysis care for the ESRD population costs Medicare 32.9 billion dollars in 2010 and it is estimated that another 14.5 billion dollars were incurred by non-Medicare patients for ESRD treatment. ${ }^{24}$ These costs continue to rise annually with more incident patients being diagnosed with ESRD. A significant portion of those charges stem from injectable medications as 2010 Centers for Medicare and Medicaid Services (CMS) paid 1.87 billion dollars for ESA injections for ESRD patients in $2010 .{ }^{24}$

In the 1980s and 1990s, CMS paid for dialysis treatments and injectable medications required for dialysis patients under separate charges. Dialysis providers were able to purchase injectable medications at a markedly discounted rate compared to the reimbursement rate allowed by government payors, which allowed a significant profit margin to be exploited by some providers. In 1992, CMS regulated this profit margin and restricted it to a $6 \%$ margin over the acquisition cost of the drug. However, the costs of dialysis-related services continued to escalate annually and therefore, in an attempt to control costs, the US Congress decided to enact global legislation to control Medicare costs. In 2008, Congress passed the Medicare Improvements for Patient and Providers Act (MIPPA), which mandated a bundling of dialysis-associated costs. Bundling was initiated in 2011 with a plan to be fully implemented by 2014. ${ }^{25}$ This bundling of services into one payment was enacted to optimize care of ESRD patients receiving dialysis treatments and to rein in the incredible costs associated with ESRD treatment. Bundling of the payment was designed to pay one fee for the entire dialysis treatment and include all injectable medications. Furthermore, MIPPA mandated a $4 \%$ total reduction of ESRD costs with bundling of services by the time the program was fully implemented in 2014. The bundle continues to evolve as CMS continues to modify the program and it is expected that oral medications used for dialysis treatment will also be included within the bundle in 2014. It remains to be seen how CMS will adjust these payments over time to account for inflation, particularly in the face of the mandated sequestration within the federal government, which was just enacted at the time of the writing of this manuscript.

As part of bundling, CMS has added clinical performance metrics called the Quality Incentive Program (QIP) designed to measure certain practice parameters to optimize outcomes. One of these QIPs will examine monthly hemoglobin levels and for those patients with persistent hemoglobin levels over $13 \mathrm{~g} / \mathrm{L}$ for 3 months or more will result in a $2 \%$ reduction of reimbursement. Although it remains nebulous as to how the bundle will fully impact clinical practice for managing anemia in ESRD patients, it appears clear there will be incentive to allow more patients to trend towards the lower side of hemoglobin target values in order to save overall costs. Currently, transfusions are not considered part of the bundled payment for ESRD and as financial pressure to minimize ESA usage increases, it is anticipated that there would be an increase in the rates of transfusions amongst ESRD patients for treatment of anemia. This could place patients at increased risk of complications as was described earlier in this manuscript.

Additionally, as pressure to decrease costs from bundling increases, particularly associated with injectable ESAs, several strategies will be appealing to the clinician. First, since it has been estimated that $50 \%$ or more of the costs associated with ESA therapies comes from utilization of nursing resources for administration and monitoring of ESAs, the greater interval between ESA medication administration will become paramount. ${ }^{26}$ Peginesatide offers a distinct advantage in this regard over all other ESA medications currently available in the United States due to its once-monthly dosing. Secondly, it has also been demonstrated that subcutaneous injection of ESA medications typically produces a more robust erythropoietic response compared to intravenous formulations. Although this does translate to increased patient discomfort, the increased erythropoietic response will translate into marginal decrease in necessary dosing that would likely result in significant cost savings for large dialysis centers with large patient populations. This must be weighed against the increased risk of developing pure red cell aplasia when using erythropoietic-based molecules. ${ }^{27}$ However, due to the unique chemical formulation of peginesatide, the risk should be mitigated, making peginesatide a suitable choice.

\section{Mechanism of action}

ESAs bind to the erythropoietin receptor and initiate a signaling cascade that promotes proliferation and maturation of erythroid precursors in the bone marrow. ${ }^{9}$ Initial rhuEPO 
formulations were hampered by a short plasma half-life (6-8 hours) requiring parenteral or intravenous administration three times weekly due to rapid metabolism. Although quite effective, this cumbersome regimen prompted efforts to develop ESAs that are both easier to administer and longer acting. Darbepoetin, launched in 2001, incorporates N-linked glycosylation sites to the erythropoietin molecule, allowing for a dosing regimen of every 1-2 weeks, but maintains the same mechanism of action. ${ }^{10}$ Methoxy polyethylene glycolepoetin beta (trade name Mircera [Roche Inc, Nutley, NJ, USA]) is a PEGylated recombinant human EPO that was introduced in Europe in 2007, but is not currently licensed in the United States. The process of pegylation allows the molecule to remain attached to the receptor for longer periods of time prior to being metabolized leading to increased half-life and dosing intervals of many pharmacological formulations. Peginesatide is a synthetic dimeric peptide that is covalently linked to polyethylene glycol (PEG). It weighs between 45.0 to $50.5 \mathrm{kDa}$; however, unlike other ESAs currently on the market, peginesatide is a peptide rather than a protein and structurally bears no homology to the rhuEPO molecule. Although peginesatide still binds to the EPO receptor and stimulates erythropoiesis just like other rhuEPO molecules, it does not stimulate immunologic activity in those patients with prior immunologic activity to rhuEPO molecules. There is also a theoretical advantage to pegylation due to shielding of the peptide from the immune system thereby decreasing immunogenicity, although this has not been specifically tested with peginesatide. ${ }^{28}$

\section{Novel strategies for anemia correction}

In recent years, there have been several new pharmacologic strategies in anemia management that are currently in various stages of planning and investigation. Peginesatide, a dimeric PEGylated peptide that activates the erythropoietin receptor, is the newest medication to come to the forefront, and will be discussed in detail later in the review. Other possible avenues for treatment include hypoxia-inducible factor (HIF) stabilization, erythropoietin gene therapy, hepcidin modulation and GATA-binding protein 2 (GATA-2) inhibition. ${ }^{29}$

HIF stabilization involves targeting the $3^{\prime}$ enhancer of the $E P O$ gene, as $E P O$ production is suppressed by oxygendependent degradation of the alpha subunit of HIF mediated by prolyl hydroxylation. EPO gene transcription can therefore be upregulated by inhibition of prolyl hydroxylation and subsequent stabilization of HIF. ${ }^{30,31}$ Several compounds have been investigated, and it has been shown that endogenous
EPO levels are increased without administration of ESA therapy, which demonstrates that the anemia in CKD is more complex than simply decreasing EPO production as the kidneys become more diseased. Defective EPO gene regulation is certainly part of the pathophysiology of anemia in CKD. Studies using HIF stabilizers have shown that erythropoietin can be generated even in anephric individuals, suggesting extrarenal sites of erythropoietin production can be induced to produce sufficient quantities of EPO to prevent anemia. ${ }^{32}$ These agents are orally active, and regulate a number of genes involved in erythropoiesis outside of the EPO gene. Another concern of HIF stabilization is the potential upregulation of other hypoxia-sensitive genes including those encoding vascular endothelial growth factor, resulting in increased rates of tumor growth and proliferative diabetic retinopathy.

GATA-2 inhibition upregulates the EPO gene and is another potential anemia treatment strategy. This family of transcription factors alleviates anemia by acting on the promoter region of the EPO gene. ${ }^{33}$ Two inhibitors have been tested in both animal models and a human hepatoma cell line demonstrating potentiated EPO production and increased hemoglobin levels. ${ }^{34,35}$ There is potential for an orally administered GATA-2 inhibitor in the future, but similar concerns about vascular endothelial growth factor gene activation as seen with HIF stabilization do exist and further investigation is needed.

Hepcidin modulation is another novel strategy, currently in the early stages of development with Phase I trials planned. Hepcidin is a small peptide produced primarily by the liver that is the primary regulator of iron metabolism in addition to having some antimicrobial properties. Upregulation of hepcidin production decreases the iron availability in the bone marrow, and there are a variety of stimuli for upregulation including inflammation, iron overload, and uremia. Dialysis patients have been demonstrated to have much higher hepcidin levels than healthy counterparts. ${ }^{36}$ Downregulation typically occurs with anemia, iron deficiency, and hypoxia, but seems to be less prevalent in patients with $\mathrm{CKD}$, perhaps due to ongoing inflammation and IL-6 production, one of the many molecules known to increase hepcidin production. Both a monoclonal antibody against hepcidin and an RNA-based antagonist of hepcidin have been created, and most recently research has focused on inhibiting production using a gene-silencing, messenger RNA sequence transcribed from the hepcidin gene to inhibit hepcidin production. ${ }^{37}$ While there is some concern that decreased hepcidin levels could increase the risk of infections in this patient population, clinical trials will be needed to determine if this risk is clinically significant. 


\section{Peginesatide: the new kid on the block}

One of the newest additions to the arsenal used to fight anemia in ESRD patients is peginesatide (Omontys, Affymax, Palo Alto, CA, USA), a synthetic, PEGylated, dimeric peptidebased ESA that acts by stimulating the erythropoietin receptor. Recently approved by the FDA for use in the dialysis patient population, this once-monthly injectable medication is the first ESA with no structural similarity to rhuEPO (Figure 1). The concept of peptide activation of the erythropoietin receptor was described in 1996 by Wrighton et al. ${ }^{38}$ Through a collaborative effort between Johnson \& Johnson (New Brunswick, NJ, USA) and Affymax, a large peptide library was screened looking for possible ligands of the erythropoietin-binding protein. Several candidate molecules were selected for further study, and erythropoietin-mimetic peptide 1 (EMP-1) was shown to have a low affinity for the receptor and low biological activity but was able to stimulate cellular proliferation of erythroid cells in culture in a dose-dependent manner and increase reticulocyte counts in animal models of erythropoiesis.

Further research aimed at increasing the biological potency of a peptide-based erythropoietin receptor agonist led to creation of peginesatide. Peginesatide is a dimeric peptide joined with a spacer linker to a pegylation chain to enhance its metabolic stability in vivo. Similar to EMP-1, peginesatide stimulates erythroid colony growth and reticulocyte counts in both rat and monkey models. ${ }^{39}$ In addition, further studies demonstrated that antibodies against erythropoietin do not crossreact with peginesatide, which was tested in a rat model of severe anemia induced by anti-EPO antibodies. ${ }^{40}$

A Phase I study evaluating the safety and pharmacodynamics of single intravenous doses of peginesatide in 28 healthy male volunteers demonstrated it was well tolerated with safety profiles comparable to that of placebo. There was a dose-dependent increase in reticulocytes with the $0.1 \mathrm{mg} / \mathrm{kg}$

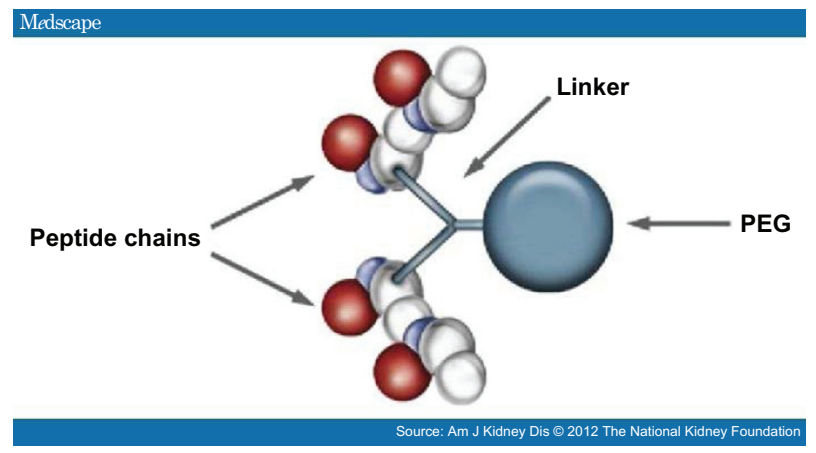

Figure I Structure of Peginesatide. ${ }^{29}$

Note: Reprinted from New anemia therapies: translating novel strategies from bench to bedside, Am J Kidney Dis. 59(3):444-45I, Macdougall I, Copyright 20I2, with permission from Elsevier.

Abbreviation: PEG, polyethylene glycol. dose associated with a statistically significant increase in hemoglobin from baseline for more than 1 month when compared to placebo. ${ }^{41}$

Peginesatide's utility in correcting anemia in CKD patients was established in a Phase II trial, with 139 CKD patients not on dialysis and not receiving ESAs in the 12 weeks prior to the study. ${ }^{42}$ This dose-finding trial involved 10 cohorts differing in body weight-based or absolute doses, intravenous versus subcutaneous administration, and administration every 2 or 4 weeks. The primary objective was to achieve hemoglobin levels between 11 and $13 \mathrm{~g} / \mathrm{dL}$. A dose-response relationship was evident for hemoglobin increase and $96 \%$ of patients across all cohorts achieved a hemoglobin response. ${ }^{42}$ Interestingly, subcutaneous and intravenous dosing produced similar responses. Those in the 2-week dosing group were more likely to have a rapid rise in hemoglobin or hemoglobin $>13 \mathrm{~g} / \mathrm{dL}$. There were serious adverse events reported in $20 \%$ of patients, including one possible drug reaction, but this was found to be consistent with routine observations in this patient population.

The Phase III clinical trial program for peginesatide involved four randomized, controlled trials with either epoetin or darbepoetin alfa as comparable therapy. Two of the studies were in CKD patients, PEARL-1 (Peginesatide for the Correction of Anemia in Patients with Chronic Renal Failure Not on Dialysis and Not Receiving Treatment with ErythropoeisisStimulating Agents) and PEARL-2, and two were in dialysis patients, EMERALD-1 (Efficacy and Safety of Peginesatide for the Maintenance Treatment of Anemia in Patients with Chronic Renal Failure Who Were Receiving Hemodialysis and Were Previously Treated with Epoetin) and EMERALD-2. A total of 2600 patients were recruited for the trials at more than 400 centers across the United States and Europe. The mean follow-up duration for patients on the study drug in the four trials was 1.3 years. The primary end points in all trials were anemia correction or hemoglobin level maintenance, and this objective was achieved in all trials. An initial analysis of a composite cardiovascular end point met the prespecified noninferiority criteria, but in a subanalysis of the two PEARL studies, there was an increased risk of developing the cardiovascular composite in patients receiving peginesatide rather than the comparator ESA (HR, 1.32). The data was published recently, and the cause of the increased incidence of adverse events in the peginesatide group when compared with darbepoetin in the $\mathrm{CKD}$ population remains unclear.

The initial study findings in all the Phase III trials indicated that peginesatide met the adjudicated composite safety end point (CSE), which was composed of death, stroke, myocardial infarction, congestive heart failure, unstable angina and arrhythmia (HR, 1.06; 90\% CI: 0.91-1.22) (Figures 2 and 3). 


\begin{tabular}{|c|c|c|}
\hline \multirow[t]{2}{*}{ Event } & $\begin{array}{l}\text { Peginesatide } \\
(\mathrm{N}=656)\end{array}$ & $\begin{array}{l}\text { Darbepoetin } \\
(\mathrm{N}=327)\end{array}$ \\
\hline & \multicolumn{2}{|c|}{ No of patients (\%) } \\
\hline \multicolumn{3}{|c|}{ Component events of the composite safety end point ${ }^{*}$} \\
\hline Death & $58(8.8)$ & $22(6.7)$ \\
\hline Cardiovascular & $8(1.2)$ & $5(1.5)$ \\
\hline Noncardiovascular & $20(3.0)$ & $12(3.7)$ \\
\hline Sudden ${ }^{\dagger}$ & $14(2.1)$ & $1(0.3)$ \\
\hline Unknown cause f $^{\ddagger}$ & $16(2.4)$ & $4(1.2)$ \\
\hline Stroke & $7(1.1)$ & $3(0.9)$ \\
\hline Myocardial infarction & $24(3.7)$ & $11(3.4)$ \\
\hline Congestive heart failure & $56(8.5)$ & $28(8.6)$ \\
\hline Unstable angina & $16(2.4)$ & $3(0.9)$ \\
\hline Arrhythmia & $37(5.6)$ & $13(4.0)$ \\
\hline \multicolumn{3}{|c|}{ Serious adverse events occurring in $\geq \mathbf{3} \%$ of patients in either group } \\
\hline Congestive cardiac failure & $56(8.5)$ & $26(8.0)$ \\
\hline Acute renal failure & $56(8.5)$ & $14(4.3)$ \\
\hline Chronic renal failure & $31(4.7)$ & $15(4.6)$ \\
\hline Pneumonia & $33(5.0)$ & $14(4.3)$ \\
\hline Urinary tract infection & $24(3.7)$ & $8(2.4)$ \\
\hline Anemia & $23(3.5)$ & $5(1.5)$ \\
\hline Hypoglycemia & $12(1.8)$ & $11(3.4)$ \\
\hline \multicolumn{3}{|c|}{ Adverse-event categories associated with the ESA class of drugs" } \\
\hline Hypertension-related events & $126(19.2)$ & $65(19.9)$ \\
\hline \multicolumn{3}{|l|}{ Thromboembolic events } \\
\hline Arterial & $39(5.9)$ & $16(4.9)$ \\
\hline Venous & $14(2.1)$ & $6(1.8)$ \\
\hline Complications related to vascular access & $11(1.7)$ & $6(1.8)$ \\
\hline Convulsions & $8(1.2)$ & $1(0.3)$ \\
\hline Infusion- or injection-related reactions & $13(2.0)$ & $4(1.2)$ \\
\hline Cancer & $31(4.7)$ & $14(4.3)$ \\
\hline
\end{tabular}

Figure 2 PEARL-I and PEARL-2: component events of the composite safety end point, most common serious adverse events, and adverse events associated with the erythropoiesis-stimulating agent (ESA) class of drugs.

Notes: *Component events of the composite safety end point were adjudicated by an independent event-review committee whose members were unaware of the treatment assignments and hemoglobin measurement; patients could have more than one event; 'sudden death was defined as nontraumatic or unexpected death within I hour after the onset of symptoms or unwitnessed death; *the cause of death was classified as unknown if the primary cause could not be determined, including those cases in which there was insufficient information; 'there were no major differences (ie, differences of $\geq 2$ percentage points) between the pooled peginesatide and darbepoetin groups with respect to serious adverse events, including those that were reported at a frequency of less than $3 \%$ in either group; "categories of adverse events associated with the ESA class of drugs were identified from the Medical Dictionary for Regulatory Activities (MedDRA) with the use of the Standardized MedDRA Query (SMQ); however, in the case of the categories of infusion- or injection-related reactions and complications related to vascular access, for which there are no suitable SMQs in MedDRA, the categories were identified according to sponsor-defined groups of preferred terms. This approach enabled the grouping of similar or related events that embodied similar clinical concepts. The proportion of patients reporting adverse events was similar in the pooled peginesatide groups ( $93.6 \%$ ) and the darbepoetin group (9l.4\%), with no major differences ( $\geq 5$ percentage points) in any individual event between groups, with the exception of back pain (which occurred in $12.0 \%$ of patients receiving peginesatide and $6.7 \%$ of patients receiving darbepoetin). From N Engl J Med. Peginesatide for anemia in patients with chronic kidney disease not receiving dialysis. Macdougall I, Provenzano R, Sharma A, et al.368:320-332. Copyright (C) (2013) Massachusetts Medical Society. Reprinted with permission from Massachusetts Medical Society. ${ }^{43}$

Abbreviation: PEARL, Peginesatide for the Correction of Anemia in Patients with Chronic Renal Failure Not on Dialysis and Not Receiving Treatment with ErythropoeisisStimulating Agents.

In the subgroup analysis of CSE events in the EMERALD trials to maintain treatment of anemia in dialysis patients, the frequency of CSE events was balanced between peginesatide and the comparator (HR, $0.95 ; 90 \%$ CI: 0.79-1.13). When this same subgroup analysis was conducted using data from the PEARL trials in nondialysis patients, the frequency of CSE events was higher in the peginesatide group $(21.6 \%)$ versus the comparator group (17.1\%) (HR, 1.34; 90\% CI: 1.03-1.73). ${ }^{43}$ The HR in the nondialysis patients was driven primarily by higher rates of death, unstable angina, and arrhythmia events in the patients treated with peginesatide. The percentages of patients experiencing stroke, myocardial infarction, and congestive heart failure were similar between treatment groups. There is further investigation of this data ongoing, but this subanalysis prompted filing of a New Drug Application (NDA) with the FDA to be limited to the dialysis patient population only, rather than the broader category of CKD.

There are several potential advantages to using peginesatide in the dialysis population, and with competitive pricing, it has the potential to become popular among the ESA market (Figure 4). The lack of antierythropoietin antibody development with the use of peginesatide may be one of its greatest 


\begin{tabular}{|c|c|c|}
\hline \multirow[t]{2}{*}{ Event } & $\begin{array}{l}\text { Peginesatide } \\
(\mathrm{N}=1066)\end{array}$ & $\begin{array}{l}\text { Epoetin } \\
(\mathrm{N}=542)\end{array}$ \\
\hline & \multicolumn{2}{|c|}{ No of patients (\%) } \\
\hline \multicolumn{3}{|c|}{ Component event of the composite safety end point ${ }^{\dagger}$} \\
\hline Death & $115(10.8)$ & $64(11.8)$ \\
\hline Cardiovascular & $31(2.9)$ & $14(2.6)$ \\
\hline Noncardiovascular & $43(4.0)$ & $24(4.4)$ \\
\hline Sudden $\ddagger$ & $26(2.4)$ & $12(2.2)$ \\
\hline Unknown cause & $15(1.4)$ & $14(2.6)$ \\
\hline Stroke & $26(2.4)$ & $20(3.7)$ \\
\hline Myocardial infarction & $49(4.6)$ & $29(5.4)$ \\
\hline Congestive heart failure & $103(9.7)$ & $49(9.0)$ \\
\hline Unstable angina & $24(2.3)$ & $12(2.2)$ \\
\hline Arrhythmia & $63(5.9)$ & $35(6.5)$ \\
\hline \multicolumn{3}{|c|}{ Serious adverse event occurring in $\geq 3 \%$ of patients in either group ${ }^{\pi}$} \\
\hline Congestive cardiac failure & $61(5.7)$ & $37(6.8)$ \\
\hline Acute myocardial infarction & $30(2.8)$ & $18(3.3)$ \\
\hline Pneumonia & $67(6.3)$ & $31(5.7)$ \\
\hline Sepsis & $35(3.3)$ & $26(4.8)$ \\
\hline Cellulitis & $34(3.2)$ & $15(2.8)$ \\
\hline Fluid overload & $41(3.3)$ & $27(5.0)$ \\
\hline Hyperkalemia & $49(4.6)$ & $23(4.2)$ \\
\hline Respiratory failure & $32(3.0)$ & $12(2.2)$ \\
\hline \multicolumn{3}{|c|}{ Adverse-event category associated with the ESA class of drugs" } \\
\hline Hypertension-related events & $208(19.5)$ & $101(18.6)$ \\
\hline \multicolumn{3}{|l|}{ Thromboembolic events } \\
\hline Arterial event & $71(6.7)$ & $48(8.9)$ \\
\hline Venous event & $21(2.0)$ & $9(1.7)$ \\
\hline Complication related to vascular access & $193(18.1)$ & $107(19.7)$ \\
\hline Convulsions & $23(2.2)$ & $11(2.0)$ \\
\hline Infusion or injection-related reactions & $32(3.0)$ & $11(2.0)$ \\
\hline Cancer & $48(3.3)$ & $23(4.2)$ \\
\hline
\end{tabular}

Figure 3 EMERALD-I and EMERALD-2: component events of the composite safety end point, most common serious adverse events, and adverse events associated with the erythropoiesis-stimulating agent (ESA) class of drugs.*

Notes: *Data are pooled from the EMERALD I and EMERALD 2 studies; ${ }^{\dagger}$ component events of the composite safety end point were adjudicated by an independent event-review committee whose members were unaware of the treatment assignments and hemoglobin levels; patients could have more than one event; ${ }^{\text {sudden death was }}$ defined as nontraumatic or unexpected death within I hour after the onset of symptoms or unwitnessed death; the cause of death was classified as unknown if the primary cause could not be determined, including those cases in which there was insufficient information; T'there were no major differences (ie, differences of $\geq 2$ percentage points) between the pooled peginesatide and epoetin groups with respect to serious adverse events, including those that were reported at a frequency of less than $3 \%$ in either group; "categories of adverse events associated with the ESA class of drugs were identified from the Medical Dictionary for Regulatory Activities (MedDRA) with the use of the Standardized MedDRA Query (SMQ); however, in the case of infusion or injection-related reactions and complications related to vascular access, for which there are no suitable SMQs in MedDRA, the categories were identified according to sponsor-defined groups of preferred terms. This approach enabled the grouping of similar or related events that embodied similar clinical concepts. The proportion of patients reporting adverse events was similar in the pooled peginesatide and epoetin groups ( $94.6 \%$ and $93.0 \%$, respectively), with no major between-group differences ( $\geq 5$ percentage points) in any individual event. From N Engl J Med. Fishbane SSB, Locatelli F, Covic AC, et al. Peginesatide in patients with anemia undergoing hemodialysis. 368:307-319. Copyright (C) (2013) Massachusetts Medical Society. Reprinted with permission from Massachusetts Medical Society. ${ }^{49}$

Abbreviation: EMERALD, Efficacy and Safety of Peginesatide for the Maintenance Treatment of Anemia in Patients with Chronic Renal Failure Who Were Receiving Hemodialysis and Were Previously Treated with Epoetin.

strengths. At the time experiments were being conducted to determine dosing in peginesatide, there was a collaborative clinical study in Europe to investigate whether it would be possible to "rescue" patients with pure red cell aplasia induced by erythropoietin administration, many of whom developed a severe transfusion-dependent anemia. Given the fact that peginesatide does not share structural homology with human erythropoietin, they postulated that patients with antierythropoietin antibodies would respond favorably to the drug. Of 14 patients enrolled, 13 of them achieved a hemoglobin $>11 \mathrm{~g} / \mathrm{dL}$ without requiring further transfusions. One patient developed antipeginesatide antibodies in addition to preexisting antierythropoietin antibodies and peginesatide had to be stopped. ${ }^{44}$

Peginesatide's long half-life can be financially advantageous and may promote its future growth. Its monthly administration may improve compliance while consuming less human resources in the outpatient dialysis setting. In addition, hospitalized patients would be less likely to require administration of the medication. The reduced number of injections could translate into decreased need for cold storage capacity, reduced risk of wastage, and risk of loss in the event of case of cold-storage interruption. Phase III trial data also 


\begin{tabular}{|c|c|c|c|}
\hline Drug & Dosage $^{a}$ & Route & $\operatorname{Cost}^{b}$ \\
\hline Peginesatide $^{c}$ & $0.04 \mathrm{mg} / \mathrm{kg}$ & IV or SC & $\$ 302.68$ \\
\hline $\begin{array}{l}\text { Omontys - } \\
\text { Affymax/Takeda }\end{array}$ & $1 \times /$ month $^{d}$ & & \\
\hline Epoetin alfa & 50-100 units/kg & IV or SC & $\$ 811.86$ \\
\hline $\begin{array}{l}\text { Procrit - Janssen } \\
\text { Epogen - Amgen }\end{array}$ & $3 \times / w k$ & & $\$ 630.00$ \\
\hline $\begin{array}{l}\text { Darbepoetin alfae } \\
\text { Aranesp - Amgen }\end{array}$ & $\begin{array}{l}0.45 \mathrm{mcg} / \mathrm{kg} \\
1 \times / \mathrm{wk} \text { or } \\
0.75 \mathrm{mcg} / \mathrm{kg} \\
\mathrm{q} 2 \mathrm{wks}\end{array}$ & IV or SC $f$ & $\$ 675.36$ \\
\hline
\end{tabular}

Figure 4 ESA price comparison. ${ }^{48}$

Notes: ${ }^{2}$ Dosage for adult CKD patients on dialysis. Initiate treatment when hemoglobin is $<10 \mathrm{~g} / \mathrm{dL}$; ${ }^{b}$ wholesale acquisition cost for 4 weeks or one month of treatment of a 70-kg patient at the lowest recommended dosage. Source: \$ource ${ }^{\circledR}$ Monthly (Selected from FDB MedKnowledge ${ }^{\mathrm{TM}}$ ) May 5, 2013. Reprinted with special permission from The Medical Letter on Drugs and Therapeutics, June II, 20I2; Vol. 54 (1392): 13. www.medicalletter.org. Actual retail prices may be higher; 'available in I to $6 \mathrm{mg} / 0.5 \mathrm{~mL}$ single-use vials or syringes and in 10- or 20-mg multiple-use vials; 'initial dose for patients not currently on an ESA. The starting monthly dose for patients already on an ESA is estimated based on the weekly dose of epoetin or darbepoetin. The package insert of Omontys includes a conversion table for these patients; ealso approved by the FDA for other indications, such as anemia in nondialysis CKD, cancer and HIV; the IV route is recommended for CKD patients on hemodialysis.

Abbreviations: IV, intravenously; SC, subcutaneously; ESA, erythropoiesis-stimulating agent; CKD, chronic kidney disease; FDA, US Food and Drug Administration.

suggest that for patients requiring very high epogen doses at baseline, perhaps due to antibody-mediated interactions, they required significantly less dose of peginesatide to achieve comparable hemoglobin. This may translate into improved outcomes for the subset of patients requiring very high dose ESA to achieve adequate hemoglobin response who are at increased risk for cardiovascular complications as noted in the TREAT subanalysis. ${ }^{45}$

One potential concern regarding peginesatide is antibody development against the PEG moiety. It has been shown that PEG can induce specific as well as nonspecific recognition by the immune system. ${ }^{46}$ This response can, of course, increase the rate of clearance of PEGylated proteins, including peginesatide. ${ }^{40} \mathrm{~A}$ recent review demonstrated that $22 \%$ to $25 \%$ of a cohort of 350 healthy blood donors had PEG antibodies, potentially due to increased exposure of the general population to $\mathrm{PEG}$-containing compounds in cosmetics, pharmaceuticals, and processed foods. ${ }^{47}$ Increased consumer use will determine if these antibodies are clinically relevant neutralizing antibodies and if they will impact efficacy of the drug.

For many practitioners, financial pressure due to the CMS bundle will cause them to consider switching patients to peginesatide due to cost of savings offered by this medication. Entering the market at a very competitive price point, combined with decreased administration time and need for less cold storage space may persuade many medical directors to consider peginesatide. With the increasing pressure to streamline the costs associated with medication administration on dialysis and simultaneously decrease the need for expensive blood transfusions in this population, peginesatide may be a useful and cost effective tool in the anemia arsenal. If administered at the recommended dose of $0.04 \mathrm{mg} / \mathrm{kg}$ monthly, Omontys is estimated to cost approximately $\$ 302$ wholesale, which is significantly less than a comparable dose of Aranesp (darbepoetin alfa) administered weekly or Procrit (Jannsen Pharmaceuticals, Inc., Tutisville, NJ, USA) (epoetin alfa) three times weekly, both of which are estimated to cost around slightly more than $\$ 700$ monthly. ${ }^{48}$ Time and widespread use will determine if it is possible to titrate hemoglobin adequately with monthly dosing, or if there will ultimately be an added burden due to financial censure for hemoglobin falling above or below goal ranges with use of this long-acting preparation.

\section{Conclusion}

Treatment of anemia remains a costly and challenging problem for renal patients and those who care for them, with many questions unanswered regarding the best approach to ESA administration and how to juggle the delicate balance between adequate hemoglobin and quality of life considerations and the concern for worsening anemia, transfusion rates on the rise and the significant costs associated with anemia management in the outpatient setting. As economic pressures to streamline costs and provide efficient and effective care increase, new strategies to help our patients maintain adequate hemoglobin levels are a welcome addition. In patients who are iron-replete and responsive to ESA administration, peginesatide may represent a new and exciting addition to the treatment algorithm for chronic anemia in ESRD.

Peginesatide had been approved for use in the dialysis patient population and was marketed under the trade name Omontys by Affymax, Inc, and Takeda Pharmaceutical Company Ltd. However, at the time of submission of this manuscript Affymax has suddenly decided to voluntarily recall the product due to a risk of severe allergic reactions and anaphylaxis. They noted $0.02 \%$ of patients had been victims of a fatal anaphylactic reaction within 30 minutes of drug administration in more than 25,000 patients who had received the drug after its FDA approval. It is currently unclear if Affymax will plan to enter the market again with a similar product that has a better safety profile in the future.

\section{Disclosure}

The authors report no conflicts of interest in this work. 


\section{References}

1. Foley R, Wang C, Collins A. Cardiovascular risk factor profiles and kidney function stage in the United States general population. The NHANES III study. Mayo Clinic Proc. 2005;80:1270-1277.

2. Krantz S. Erythropoietin. Blood Purif. 1991;77:419-434.

3. Bernhardt W, Wiesener M, Scigalla P, et al. Inhibition of prolyl hydroxylases increases erythropoietin production in ESRD. J Am Soc Nephrol. 2010;12:2151-2156.

4. Foley R, Parfrey P, Harnett J, Kent G, Murray D, Barre P. The impact of anemia on cardiomyopathy, morbidity, and and mortality in end-stage renal disease. AmJ Kidney Dis. 1996;1:53-61.

5. Locatelli F, Aljama P, Barany P, et al. Revised European best practice guidelines for the management of anaemia in patients with chronic renal failure. Nephrol Dial Transplant. 2004;19(Suppl 2):1-47.

6. Besarab A. Treatment of Anemia in Dialysis Patients. 3rd ed. Baltimore, MD: Lippincott Williams \& Wilkins; 2004.

7. Lemy A, Andrien M, Wissing K, et al. Major histocompatability complex class 1 chain-related antigen a antibodies: sensitizing events and impact on renal graft outcomes. Transplantation. 2010;90(2):168-174.

8. Lankhorst C, Wish J. Anemia in renal disease: diagnosis and management. Blood Rev. 2009;24:39-47.

9. Koury M, Bondurant M. The molecular mechanism of erythropoietin action. Eur J Biochem. 1992;201:649-663.

10. Macdougall I. Novel erythropoiesis-stimulating agents: a new era in anemia management. Clin J Am Soc Nephrol. 2008;3:200-207.

11. Collins A, Li S, St Peter W, et al. Death, hospitalization and economic associations among incident hemodialysis patients with hematocrit values of 36 to 39\%. J Am Soc Nephrol. 2001;12:2465-2473.

12. Singh A, Szczech L, Tang K, et al. Correction of anemia with epoetin alfa in chronic kidney disease. N Engl J Med. 2006;355:2085-2098.

13. Drueke T, Locatelli F, CLyne N, et al. Normalization of hemoglobin level in patients with chronic kidney disease and anemia. NEngl J Med. 2006;355:2071-2084.

14. Besarab A, Bolton W, Browne J, et al. The effects of normal as compared with low hematocrit values in patients with cardiac disease who are receiving hemodialysis and epoetin. $N$ Engl J Med. 1998;339: 584-590.

15. Strippoli G, Craig J, Manno C, Schena F. Hemoglobin targets for the anemia of chronic kidney disease: a meta-analysis of randomized, controlled trials. J Am Soc Nephrol. 2004;12:3154-3165.

16. Jones M, Ibels L, Schenkel B, Zagari M. Impact of epoetin alfa on clinical end points in patients with chronic renal failure: a meta-analysis. Kidney Int. 2004;65(3):757-767.

17. Szczech L, Barnhart H, Inrig J, et al. Secondary analysis of the CHOIR trial epoetin-alpha dose and achieved hemoglobin outcomes. Kidney Int. 2008;74:791-798.

18. KDOQI. NKF/KDOQI Clinical Practice Guidelines and clinical practice recommendations for anemia in chronic kidney disease: 2007 update of hemoglobin target. Am J Kidney Dis. 2007;50:471-530.

19. Pfeffer M, Burdmann E, Chen C, et al. A trial of darbepoetin alfa in type 2 diabetes and chronic kidney disease. $N$ Engl J Med. 2009;361: 2019-2032.

20. Kapoian T, O’Mara N, Singh A, et al. Ferric gluconate reduces epoetin requirements in hemodialysis patients with elevated ferritin. J Am Soc Nephrol. 2008;19:372-379.

21. Lawler E, Bradbury B, Fonda J, Gaziano J, Gagnon D. Transfusion burden among patients with chronic kidney disease and anemia. Clin J Am Soc Nephrol. 2010;5:667-672.

22. Spiegel D, Khan I, Krishan M, Mayne T. Changes in hemoglobin level distribution in US dialysis patients from June 2006 to November 2008. Am J Kidney Dis. 2010;55:113-120.

23. National Kidney Foundation/Kidney Disease: Improving Global Outcomes. KDIGO Clinical Practice Guideline for Anemia in Chronic Kidney Disease. Kidney Int. 2012;2:279-331. http://www.kdigo.org/ clinical_practice_guidelines/anemia.php.
24. National Institutes of Health. USRDS 2012 Annual Data Report: Atlas of Chronic Kidney Disease and End-Stage Renal Disease in the United States. Bethesda, MD: US Renal Data System; 2012.

25. Medicare program; end-stage renal disease prospective payment system, quality incentive program, and bad debt reductions for all Medicare providers: final rule. Centers for Medicare and Medicaid Services (CMS), HHS; 2012.

26. Saueressig U, Kwan J, De Cock E, Sapede C. Healthcare resource utilization for anemia management: current practice with erythropoiesisstimulating agents and the impact of converting to once-monthly C.E.R.A. Blood Purif. 2008;26:537-546.

27. Chow K, Szeto C, Li P. Intravenous versus subcutaneous EPO: Anything to do with pure red cell aplasia complications. Am J Kidney Dis. 2003;41:266-267.

28. Katre N. Immunogenicity of recombinant IL-2 modified by covalent attachment of polyethylene glycol. J Immunol. 1990;144:209-213.

29. Macdougall I. New anemia therapies: translating novel strategies from bench to bedside. Am J Kidney Dis. 2012;59(3):444-451.

30. Schofield C, Ratcliffe P. Oxygen sensing by HIF hydroxylases. Nat Rev Mol Cell Biol. 2004;5:43-54.

31. Nangaku M, Kojima I, Tanaka T, Ohse T, Kato H, Fujita T. Novel drugs and the response to hypoxia: HIF stabilizers and prolyl hydroxylase. Recent Pat Cardiovasc Drug Discov. 2006;1:129-139.

32. Nangaku M, Eckardt K-U. Pathogenesis of renal anemia. Semin Nephrol. 2006;26:261-268.

33. La Ferla K, Reimann C, Jeikmann W, Hellwig-Burgel T. Inhibition of erythropoietin gene expression signaling involves the transcription factors GATA-2 and NF-kappaB. FASEB J. 2002;13:1811-1813.

34. Imagawa $\mathrm{S}$, Nakano $\mathrm{Y}$, Obara $\mathrm{N}$, et al. A GATA-specific inhibitor (K-7174) rescues anemia induced by IL-1beta, TNF-alpha, or L-NMMA. FASEB J. 2003;17(12):1742-1744.

35. Nakano Y, Imagawa S, Matsumoto K, et al. Oral administration of K-11706 inhibitis GATA binding activity, enhances hypoxia-inducible factor 1 binding activity, and restores indicators in an in vivo mouse model of anemia of chronic disease. Blood Purif. 2004;104(13): 4300-4307.

36. Macdougall J, Malyszko J, Hider R, Bansal S. Current status of the measurement of blood hepcidin levels in chronic kidney disease. Clin J Am Soc Nephrol. 2010;5(9):1681-1689.

37. Sasu B, Cooke K, Arvedson T, et al. Antihepcidin antibody treatment modulates iron metabolism and is effective in a mouse model of inflammation-induced anemia. Blood. 2010;115(17):3616-3624.

38. Wrighton N, Farrel F, Chang R, et al. Small peptides as potent mimetics of the protein hormone erythropoietin. Science. 1996;273(5274): 458-464.

39. Fan Q, Leuther K, Holmes C, et al. Preclinical evaluation of Hematide, a novel erythropoiesis stimulating agent, for the treatment of anemia. Exp Hematol. 2006; 10:1303-1311.

40. Woodburn K, Fan Q, Winslow S, et al. Hematide is immunologically distinct from erythropoietin and corrects anemia induced by antierythropoietin antibodies in a rat pure red cell aplasia model. Exp Hematol. 2007;35(8):1201-1208.

41. Stead R, Lambert J, Wessels D, et al. Evaluation of the safety and pharmacodynamics of Hematide, a novel erythropoietic agent in a phase 1, double-blind, placebo-controlled, dose-escalation study in healthy volunteers. Blood. 2006;108(6):1830-1834.

42. Macdougall I, Wiecek A, Tucker B, et al. Dose-finding study of peginesatide for anemia correction in chronic kidney disease patients. Clin J Am Soc Nephrol. 2011;6:2579-2586.

43. Macdougall I, Provenzano R, Sharma A, et al. Peginesatide for anemia in patients with chronic kidney disease not receiving dialysis. $N$ Engl J Med. 2013;368:320-332.

44. Macdougall I, Rossert J, Casadevall N, et al. A peptide-based erythropoietin-receptor agonist for pure red-cell aplasia. NEngl J Med. 2009;361(19):1848-1855. 
45. Locatelli F, Aljama P, Canaud B, et al. Target haemoglobin to aim for with erythropoiesis-stimulating agents: a position statement by ERBP following publication of the Trial to reduce cardiovascular events with Aranesp therapy (TREAT) study. Nephrol Dial Transplant. 2010;9:2846-2850.

46. Yang B, Lum P, Hayashi M, Roskos L. Polyethylene glycol modification of filgrastim results in decreased renal clearance of the protein in rats. J Pharm Sci. 2004;93(5):1367-1373.
47. Garratty G. Modulating the red cell membrane to produce universal/ stealth donor red cells suitable for transfusion. Vox Sang. 2008;94(2): 87-95.

48. Peginesatide (Omontys) for anemia in chronic kidney disease. Med Lett Drugs Ther. 2012;54(1392):45-46.

49. Fishbane SSB, Locatelli F, Covic AC, et al. Peginesatide in patients with anemia undergoing hemodialysis. N Engl J Med. 2013;368:307-319.
International Journal of Nanomedicine

\section{Publish your work in this journal}

The International Journal of Nanomedicine is an international, peerreviewed journal focusing on the application of nanotechnology in diagnostics, therapeutics, and drug delivery systems throughout the biomedical field. This journal is indexed on PubMed Central, MedLine, CAS, SciSearch $\AA$, Current Contents ${ } /$ Clinical Medicine,

\section{Dovepress}

Journal Citation Reports/Science Edition, EMBase, Scopus and the Elsevier Bibliographic databases. The manuscript management system is completely online and includes a very quick and fair peer-review system, which is all easy to use. Visit http://www.dovepress.com/ testimonials.php to read real quotes from published authors.

Submit your manuscript here: http://www.dovepress.com/international-journal-of-nanomedicine-journal 